\title{
Interprofessional Practice Approach between Social Work and Pharmacy
}

\author{
Abimbola Farinde, PhD., PharmD \\ Columbia Southern University \\ Orange Beach, AL, USA \\ E-mail: Abimbola.Farinde@columbiasouthern.edu
}

\author{
Kelly N. Gable, PharmD., BCPP \\ Southern Illinois University Edwardsville, School of Pharmacy \\ 200 University Park Drive, Edwardsville, IL 62026, USA \\ E-mail:kgable@siue.edu
}

Received: March 12, 2014 Accepted: June 1, 2014 Published: June 6, 2014

doi:10.5296/ijsw.v1i1.5777

URL: http://dx.doi.org/10.5296/ijsw.v1i1.5777

\begin{abstract}
The comprehensive and patient-centered management of dementia patients requires the collaborative efforts of various disciplines. An emphasis can be placed on interprofessional relationship that exists among the disciplines of psychiatry, pharmacy, and psychology as it relates to the management of the observable behavioral and psychological disturbances of the disorder. The ability to achieve a positive therapeutic outcome with dementia patients generally involves the active participation of multiple disciplines given the complex and progressive nature of dementia. The existing literature has extensively examined the relationship that exists between nurses and physicians and the observed successes that have been identified with this collaboration has been extrapolated to other health care professions. This article will seek to examine the benefits that can be reaped from the involvement of psychiatry, pharmacy, and psychology in providing a focused and integrated approach to the management of patients with dementia.
\end{abstract}

Keywords: interprofessional practice, dementia, pharmacist, social worker, collaboration 


\section{Introduction to Interprofessional Relationships}

Within the mental healthcare system, collaboration among professionals is vital to providing comprehensive and patient-centered psychiatric care. The effective and efficient delivery of best practice care in most healthcare systems is influenced by the existence of a collaborative practice (Pullon, 2008). In turn a collaborative practice and the presence of teamwork can be dependent on interpersonal relationships between various disciplinary groups (Pull-on, 2008; Thylefors, Persson, \& Hellstrom, 2005). Common collaborative efforts that have been described include the interprofessional relationship of the nurse and physician. The relationships that have been described between nurses and doctors has led to an improved understanding of and respect for the professional roles among differing professions, and the complexity of the interaction between the these professionals which is important if interprofessional collaboration is to exist (Salvage, 2000; Davies, 2002). Over time, a professional identity has developed through professional interactions and these serve as the basis for the understanding interprofessional relationships not only between nurses and doctors but other health care professions (Davies, 2002). The presence of respect and trust are presumed precursors for successful internprofessional relationships that do not remain static but are subject to change as a result of past experiences, situation specific healthcare related cases, and current experiences (Nielson, 2004; Pullon, 2005). Collaboration among diverse perssonel is one way to promote a comprehensive and continuous approach to mental health care (Bruner, Waite, \& Davey, 2011). While interprofessonal collaboration is recognized as a key element in the development of initiatives that are designed to increase the effectiveness of health care services, rarely, is the relationship of the social worker and clinical pharmacist documented in the literature but benefits in patient care may be achieved through the existence of this collaborative effort (D'Amour et al., 2005). Given the increasingly complex health care problems that health care professionals faces, it is important for varying disciplines to come together to optimize patient care (D'Amour et al., 2005). Interprofessional collaboration among clinical pharmacist and social workers requires the ability to make changes from the primarily discipline-based vision that most professions possess to the adoption of a logic of collaboration and a share common goal (DeMarco, Horowitz, \& McLeod, 2000; D'Amour et al., 2005).

\section{Establishment of Interprofesional Approach to Patient Care}

The development of interprofessional communication and collaboration is recognized as a fundamental aspect of improving patient care and meeting the increasing demands of a complex care system (Rice et al., 2010). Interprofessional collaboration is defined as an active relationship between two or more health and social care professions who work together to solve problems or provide services (Zwarenstein \& Reeves, 2006). The integration of various disciplines appears to be even more pivotal when it comes to the delivery of patient-centered psychiatric care. The failures that can develop from inappropriate collaboration and communication among health care professional can have a negative impact on health care outcomes, diminish the value of clinical decisions, and create errors when it comes to implementing decisions (Baggs et al., 1992; Zwarenstein \& Reeves, 2006). Ultimately, the given the complex interpersonal nature of all health care delivery, 
interventions that are directed at one professional group can have an impact on the work of other professional group (Baggs et al., 1992). A good interpersonal collaboration will enable one profession to effectively report to another about patients' conditions that may require immediate intervention, and if not under less collaborative conditions this may be neglected (Baggs et al., 1992; Zwarenstein \& Reeves, 2006).

\section{Examination of the Role of Clinical Pharmacist and Social Worker}

Within the realm of the mental healthcare system, the relationship between the clinical pharmacist and social worker has not garnered much attention in the literature largely as a result of the lack of awareness about the collaboration between social work and pharmacy. Even though social workers provide approximately half of all mental health services in the United States, the comparison of social work with other disciplines have indicated that they are generally viewed to be less effective when comes to the management and/or treatment of certain mental health disorders (National Association of Social Workers, 2002; Rubin \& Parrish, 2012). Firstly, there is the misconception or misrepresentation of social workers and what they can do (National Association of Social Workers, 2002; National Association of Social Workers, 2004). The discipline of social work requires the availability of human service workers that are well-trained to address complex social issues with expertise in organization, development, and interpersonal skills that lead to improved patient care outcomes (Nandan \& Scott, 2013). The social work discipline strives to promote social change, problem solving in human relationships with the principle of human rights and social justice being at its core. This principle is recognized in the actions of social workers that work diligently to provide individuals who suffer from mental health related issues with adequate treatment (British Association of Social Workers, 2002; Dickens, 2012). In order for social work interventions within the mental healthcare system to be effective it requires practitioners to consider both social and physical environment, with its problems, supports, and opportunities and within recent years the field of social work, geography of mental health, and psychiatry has made substantial progress in the movement towards this conceptualization (Hudson, 2012). On the other spectrum is the discipline of pharmacy, which in comparison to social work has experienced some misconceptions. Pharmacist possess a unique knowledge base that can be beneficial to the interdisciplinary approach to mental health care management as a result of the training, education, and knowledge of pharmacology and therapeutics of drugs and thus the varied and integrated expert knowledge allows them to make professional judgments and recommendations relating to the selection of psychoactive medications (Harding \& Taylor, 2004; Waterfield, 2010). As pharmacy is generally not a well-understood profession but a study that examined the expanding role of pharmacists revealed a range of attitudes from support for involvement in non-dispensing roles such as public health to less support for services that require access to specific information from medical records (Iversen, Mollison, \& MacLeod, 2001; Waterfield, 2010). Ultimately, the expanding role of the pharmacy profession has demonstrated that it is a profession in which there is an understood professional authority over the lay person, adequate competency, and a theoretical knowledge that serves as the underlying basis for the profession (Dingwall, \& Wilson, 1995; Iversen, Mollison, \& MacLeod, 2001; Waterfield, 
2010).

\subsection{Integration of Disciplines and Identification of Roles}

Within the dynamics of a mental health care management team, the interdisciplinary approach to patient care should foster better therapeutic outcomes than care that is provided by an individual professional (Craven \& Bland, 2006). An interdisciplinary approach should be based on the construction of a collective action that work to meet the complex mental health needs of clients through the integration of differing professional perspectives. It is important that each professional has a clear understanding of how they can contribute to the care of the patients with mental illness and to also improve professional skills in supporting treatment initiatives (Mental Health Professionals' Association, 2008; King et al., 2013). While it may be an initial challenge to establish the relationship between social worker and pharmacists that are integral to collaborative care, once established it can help to foster an ongoing collaborative clinical approach through the promotion of interdisciplinary communication to the provision of mental health care (Mental Health Professionals' Association, 2008; King et al., 2013).

In the interdisciplinary team, the role of the social worker primarily focuses on identifying any and all resources that can assist the patient from making the transition from inpatient to outpatient and increase the likelihood of their functionality in the general public (Paradis, 1987). The social worker can assist with the identification of outpatient treatment programs that help to decrease the probability of relapse, enforce medical compliance, and engage in continuous monitoring postdischarge. This can consist of increasing awareness about mental health stressors and strategies to cope and working diligently to prevent or minimize the occurrence of mental health problems (Khapardes, 2012). The role of the clinical pharmacist can focus on identifying and providing recommendations for psychotropic medications that are well suited for patients based on patient-specific characteristics and working in conjunction with the social worker to ensure that medication interventions are implemented and compliance can be maintained (Gregor, 2010).

\section{Opportunities for Collaboration}

A trusting-pharmacist-social worker alliance can be formed to prevent missed dosages and relapse (Gable, Muhlstadt, \& Celio, 2011). Since patients with mental illnesses often face significant barriers that can include poor insight, complicated medication regimen, and serious adverse effects that can lead to poor treatment outcomes. The collaboration between clinical pharmacists and social workers can develop preventive measures beforehand to curtail incidences of occurrence (Compton et al., 2005; Gable, Muhlstadt, \& Celio, 2011). The collaborative efforts between a social worker and pharmacist can arise during periods of medication initiation and ways to increase the likelihood that adherence is maintained during the course of therapy. Opportunities for arise when both professions have a primary initiative which is to optimize patient treatment outcomes and maintain continuity of mental health care. 


\section{What Ties the Disciplines Together?}

The discipline of social works seeks to improve an individual's or group's well-being, condition, or quality of life through community organization, research, policy, or direct practice. The long held belief is that social work involves the ability to make appropriate referrals that is concerned and caring contribution to the wellbeing of a client (Sands, 2000). Historically, psychiatrists have received much of the attention in the role of "expert" witness on the subject of mental health, but substantial number of social workers are functioning within the space of mental health concepts (Hughes \& O'Neal, 1983). Pharmacists are already well-known for their role as drug information specialists and social workers can provide timely referrals for psychotropic medications. A national survey of clinical social workers confirmed that this activity is one of the most frequently performed social work roles related to medication management, and $89.2 \%$ felt confident in this role. This degree of comfort that social workers express with their role in medication management can only serve to promote the healthcare exchange between the two disciplines (Bentley, Walsh, \& Farmer, 2005).

\section{Example Scenarios of Collaboration}

\subsection{The Outreach Worker}

Jason M. is a 45 year-old homeless male presenting to the outreach social worker at a local shelter. The outreach worker quickly recognizes the core features of psychosis present. Jason is very disorganized in thought and appearance, paranoid, and responding to internal stimuli. After a brief interaction and engagement, the social worker discovers that Jason has not received his antipsychotic medication in 2 weeks. This is due to his prescription coverage being temporarily discontinued. The clinical pharmacist was phoned to discuss possible ways to obtain medication for this client. The pharmacist reviewed his previous antipsychotic medications and was able to initiate a medication through accessing antipsychotic samples.

\subsection{The Therapist}

Sara C. is a 27 year-old female routinely receiving psychotherapy from a licensed clinical social worker (LCSW). During a therapy session, the therapist notices that Sara is very fidgety, having difficulty maintaining focus, and appears extremely restless. The therapist also identifies that the client's aripiprazole (Abilify) was recently increased. Upon further assessment by the clinical pharmacist, akathisia, an adverse effect from the antipsychotic was identified. The dose was subsequently lowered and the client was able to successfully resume therapy one week later.

\section{Conclusion}

The interprofessional relationship between pharmacists and social workers is not one that has been extensively studied in the literature when compared to other well-known collaboration but the presence of this relationship can produce benefits in the treatment of individuals with mental health related issues. Some of the benefits include timely referrals, more frequent consultations related to psychotropic medications, and the opportunity for improved patient care outcomes. 


\section{References}

Baggs, J., Ryan, S., Phelps, C., Richeson, J., \& Johnson, J. (1992). The association between interdisciplinary collaboration and patient outcomes in a medical intensive care unit. Heart Lung, 21, 18-24.

BASW [British Association of Social Workers]. (2002). Code of ethics. [Online] Available: http://www.basw.co.uk/about/ codeofethics/

Bentley, K., Walsh, J., \& Farmer, R. (2005). Referring Clients for Psychiatric Medication: Best Practices for Social Workers. Best Practice in Mental Health [serial online], 2005, 1(1), 59-71.

Bruner, P., Waite, R., \& Davey, M. (2011). Providers' perspectives on collaboration. International Journal of Integrated Care, 11, 1-11.

Compton, M. T., Rudisch, B. E., Weiss, P. S., West, J. C., \& Kaslow, N. J. (2005). Predictors of psychiatrist-reported treatment-compliance problemsamong patients in routine US psychiatric care $\quad$ Psychiatry Res, 29-36. http://dx.doi.org/10.1016/j.psychres.2005.07.009

Craven, M., \& Bland, R. (2006). Better practices in collaborative mental health care: an analysis of the evidence base. Can J Psychiatry, 51, 1S-73S.

D’Amour, D., Ferrada-Videla, M., San Martin Rodriguez, L., \& Beaulieu, M. (2005). The conceptual basis for interprofessional collaboration: Core concepts and theoretical framework. Journal of Interprofessional Care, Supplement 1, 116-131. http://dx.doi.org/10.1080/13561820500082529

Davies, C. (2002). Workers, professions and identities. In J. Henderson \& D. Atkinson (Eds.), Managing care in context. London: Routledge.

DeMarco, R., Horowitz, J. A., \& McLeod, D. (2000). A call to interprofessional alliances. Nursing Outlook, 48, 172-178. http://dx.doi.org/10.1067/mno.2000.103104

Dickens, J. (2012). The definition of social work in the United Kingdom, 2000-2010. International Journal of Social Welfare [serial online], 21(1), 34-43. http://dx.doi.org/10.1111/j.1468-2397.2011.00782.x

Dingwall, R., \& Wilson, E. (1995). Is pharmacy really an incomplete profession? Perspect Soc Problems, 7, 111-28.

Gable, K., Muhlstadt, K., \& Celio, M. (2011). A Mental Health Elective to Improve Pharmacy Students' Perspectives on Mental Illness. American Journal of Pharmaceutical Education, 75(2), 1-6. http://dx.doi.org/10.5688/ajpe75234

Gregor, C. (2010). Unconscious Aspects of Statutory Mental Health Social Work: Emotional Labour and the Approved Mental Health Professional. Journal of Social Work Practice, 24(4), 429-443. http://dx.doi.org/10.1080/02650531003791012 
Harding, G., \& Taylor, K. (2004). Pharmacy's strength lies in its blend of clinical, scientific and social skills. Pharm J., 273(7310), 146.

Hudson, C. (2012). Disparities in the Geography of Mental Health: Implications for Social Work. Social Work, 57(2), 107-119. http://dx.doi.org/10.1093/sw/sws001

Hughes, D., \& O'Neal, B. (1983). A Survey of Current Forensic Social Work. Social Work, 28(5), 393-395.

Iversen, L., Mollison, J., \& MacLeod, T. N. N. (2001). Attitudes of the general public to the expanding role of community pharmacists: a pilot study. Fam Pract, 18(5), 534-6. http://dx.doi.org/10.1093/fampra/18.5.534

Khapardes, S. (2012). Mental health among rural people and social work intervention. Indian Streams Research Journal, 2(10), 1-6.

King, K., Christo, J., Fletcher, J., Machlin, A., Nicholas, A., \& Pirkis, J. (2013). The sustainability of an Australian initiative designed to improve interdisciplinary collaboration in mental health care. International Journal of Mental Health Systems, 7(1), 1-11. http://dx.doi.org/10.1186/1752-4458-7-10

Mental Health Professionals' Association: Collaborative mental health care: education and training for interdisciplinary networks: Participants' manual. Melbourne: Mental Health Professionals' Association; 2008.

Nandan, M., \& Scott, P. (2013). Social Entrepreneurship and Social Work: The Need for a Transdisciplinary Educational Model. Administration in Social Work [serial online], 37(3), 257-271. http://dx.doi.org/10.1080/03643107.2012.684428

National Association of Social Workers. (2002). Social workers increase mental health awareness. [Online] Available: http://naswdc.org/pressroom/2002/050102

National Association of Social Workers. (2004). Perceptions of profession are analyzed. NASW News, 49, p. 10. [Online] Available: http://www.socialworkers.

Nielson, B. (2004). The role of trust in collaborative relationships: A multi-dimensional approach. Management, 7(3), 239-256.

Paradis B. (1987). An Integrated Team Approach to Community Mental Health. Social Work [serial online], 32(2), 101-104.

Pullon, S. (2008). Competence, respect and trust: Key features of successful interprofessional nurse-doctor relationships. Journal of Interprofessional Care, 22(2), 133-147. http://dx.doi.org/10.1080/13561820701795069

Rice, K., Zwarenstein, M., Conn, L., Kenaszchuk, C., Russell, A., \& Reeves, S. (2010). An intervention to improve interprofessional collaboration and communications: A comparative qualitative study. Journal of Interprofessional Care, 24(4), 350-361. http://dx.doi.org/10.3109/13561820903550713 


\section{Macrothink}

International Journal of Social Work

ISSN 2332-7278

2014, Vol. 1, No. 1

Rubin, A., \& Parrish, D. (2012). Comparing Social Worker and Non-Social Worker Outcomes: A Research Review. Social Work [serial online], 57(4), 309-320. http://dx.doi.org/10.1093/sw/sws015

Salvage, J. (2000). Jointly and severally. Nursing Times, 96(27), 26.

Sands, H. (2000). Make a referral. In G. Ahlskog \& H. Sands (Eds.), The guide to pastoral counseling and Care, 361-378. Madison, CT: Psychosocial Press.

Thylefors, I., Persson, O., \& Hellstrom, D. (2005). Team types, perceived efficiency and team climate in Swedish cross-professional teamwork. Journal of Interprofessional Care, 19(2), 102-114. http://dx.doi.org/10.1080/13561820400024159

Waterfield, J. (2010). Is Pharmacy a Knowledge-Based Profession?. American Journal of Pharmaceutical Education [serial online], 74(3), 1-6. http://dx.doi.org/10.5688/aj740350

Zwarenstein, M., \& Reeves, S. (2006). Knowledge translation and interprofessional collaboration: Where the rubber of evidence-based care hits the road of teamwork. Journal of Continuing Education in the Health Professions [serial online], 26(1), 46-54.

\section{Copyright Disclaimer}

Copyright reserved by the author(s).

This article is an open-access article distributed under the terms and conditions of the Creative Commons Attribution license (http://creativecommons.org/licenses/by/3.0/). 